\title{
Parboiled germinated rice production using a new method
}

\author{
Thatchapol Chungcharoen ${ }^{1}$, Pornpit Onboon ${ }^{1}$, and Sansanee Sansiribhan ${ }^{2 *}$ \\ ${ }^{1}$ King Mongkut's Institute of Technology Ladkrabang, Prince of Chumphon Campus, Department of \\ Engineering, Chumphon, Thailand \\ ${ }^{2}$ Suan Sunandha Rajabhat University, Applied Physics Program, Faculty of Science and Technology, \\ Bangkok, Thailand
}

\begin{abstract}
The process complexity is the main problem for parboiled germinated rice (PGR) production. The PGR production using the new method (germinating and drying using hot air fluidized bed combined with halogen lamp) can decrease the complexity of process and also provided the good quality of PGR when comparing with PGR production using traditional method (germinating, steaming and drying using hot air fluidized bed). The new method provided the higher drying rate, leading to faster decrease of moisture content and higher increase of grain temperature. This caused the lower whiteness index. It also provided the lower degree of gelatinization. However, the percentage of head rice yield of PGR with new method was not significantly different when comparing with PGR production using traditional method. For Specific Energy Consumption (SEC), the PGR production using the new method provided the lower SEC value than PGR production using traditional method.
\end{abstract}

\section{Introduction}

Parboiled rice $(\mathrm{PR})$ is a rice product that has been cooked through a hydrothermal process to gelatinize starch component of rice. It is aimed to improve the rice quality for reducing the breakage susceptibility of rice during the dehulling and milling processes [1]. However, the PR which is produced in Thailand are exported to other countries rather than domestic sales because the texture of PR after cooking is harder than white rice and brown rice [2]. This causes the low acceptance of Thai consumer. In this research, the paddy would be germinated before parboiling to improve the texture of PR after cooking. This should help Thai people to consume more PR because of softer texture [3]. Moreover, the germination process also helps to increase the amount of beneficial nutrients.

Traditional method for parboiled germinated rice (PGR) production consists of three main steps: germinating, steaming and drying [4]. Steaming is an important step that adds heat and moisture to the paddy which is soaked in hot water by using the saturated steam from the boiler. It provides the gelatinization in the rice grain, leading to increase head rice yield of milled rice [5]. However, using steam in the steaming process to produce PGR is a complex system because it has to control the temperature, pressure and steaming time. These

* Corresponding author: sansanee.sa@ssru.ac.th 
factors directly affect the quality of PR [6]. Moreover, the parboiling with steaming has also a high cost production. To solve the complexity of steaming process, the hot air fluidized bed technique combined with halogen lamp is used for PGR production.

Fluidized bed drying is a highly efficient drying which provides excellent mixing between the paddy and hot air. The drying with the hot air fluidized bed technique would evaporate the moisture in the rice grain from the surface to the inside of paddy [7] while the halogen lamp provides the heat in the form of infrared radiation to evaporate the moisture in the rice grain from the inside to the surface of paddy [8]. These would create a complete gelatinization without steaming process. The objective of this study was therefore to produce the PGR using the new method (germinating and drying using hot air fluidized bed combined with halogen lamp). The assessment of the PGR quality was considered in terms of the head rice yield and whiteness index. The drying characteristics and drying rates were also investigated. These were compared with PGR produced by traditional method (germinating, steaming and drying using hot air fluidized bed).

\section{Materials and methods}

\subsection{Materials}

Suphanburi 1 rice from the Rice Seeds Center, Ratchaburi, Thailand was selected for this study. It had already stored for at least 3 months before testing. The moisture content of paddy was about $13 \%$ d.b..

\subsection{Experimental setup}

The sample was dried in a hot air fluidized bed dryer which installed the halogen lamp as shown in Figure 1. The drying chamber is a cylindrical with an inside diameter of $20 \mathrm{~cm}$ and a height of $100 \mathrm{~cm}$. The halogen lamp is installed on the side of drying chamber. It has 2 halogen lamp of $1,500 \mathrm{~W}$ and 2 halogen lamp of $500 \mathrm{~W}$. The heat of drying is created and controlled by a $15 \mathrm{~kW}$ heater and PID controller with an accuracy of $\pm 1^{\circ} \mathrm{C}$. The air is drawn into drying chamber using a backward-curved blade centrifugal fan that is driven by a 1.5 $\mathrm{kW}$ motor. The amount of exhaust air about $80 \%$ was recycled for drying.

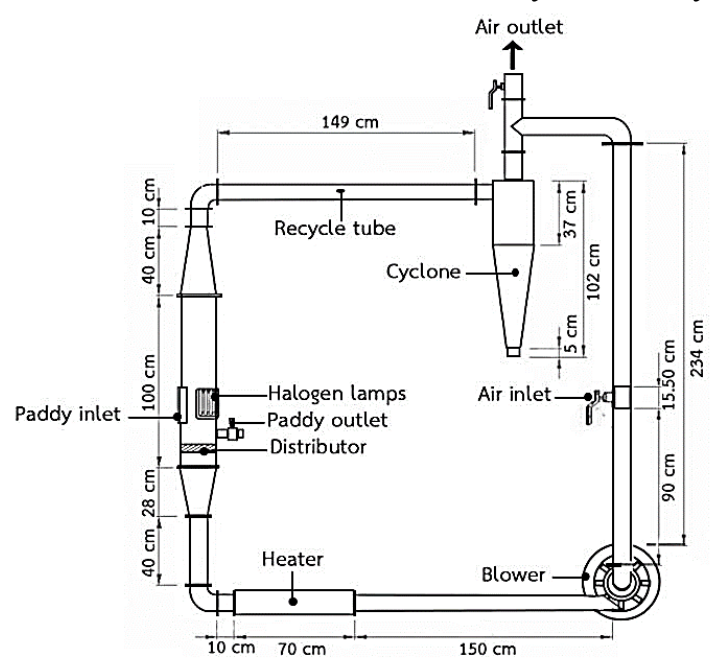

Fig. 1. Schematic diagram of hot air fluidized bed dryer combined with halogen lamps. 


\subsection{Preparation of PGR sample}

Paddy was germinated by controlling the temperature of soaking water at $35^{\circ} \mathrm{C}$ for 44 hours, which can be observed the germination percentage of 95. For PGR produced by traditional method, the germinated paddy was steamed using the Autoclave (Model LS-35LJ) at steaming temperature of $103^{\circ} \mathrm{C}$ for $15 \mathrm{~min}$. After that, $1.8 \mathrm{~kg}$ of steamed paddy sample was dried using hot air fluidized bed dryer at drying temperature of $170^{\circ} \mathrm{C}$. For PGR produced by new method (fluidized bed drying technique combined with halogen lamps), the germinated paddy without steaming was dried using hot air fluidized bed dryer with halogen lamps at drying temperature of $170^{\circ} \mathrm{C}$ and wattage of halogen lamp at $4,000 \mathrm{~W}$. The sample in both methods was dried to moisture content of $22 \%$ d.b. and then tempered for 30 min. Finally, the tempered sample was dried in the shade to moisture content of $13-15 \%$ d.b.

\subsection{Quality determinations}

\subsubsection{Gelatinization properties}

The degree of gelatinization (DG) was measured by Differential Scanning Calorimeter (DSC). It was determined by comparing the change of enthalpy $(\Delta \mathrm{H})$ in PGR to that in sample without treatment (raw rice). The equation was calculated as shown in Equation (1) [9].

$$
D G=\left[1-\left(\Delta H_{\mathrm{PGR}} / \Delta H_{\mathrm{r})}\right] x 100\right.
$$

Where, $\Delta H_{\mathrm{PGR}}$ is the transition enthalpy of PGR ( $\mathrm{J} / \mathrm{g}$ dry matter), $\Delta H_{\mathrm{r}}$ is the transition enthalpy of raw rice ( $\mathrm{J} / \mathrm{g}$ dry matter)

\subsubsection{Head rice yield}

The head rice yield (HRY) was defined as the weight of unbroken white rice kernels (a length longer than $3 / 4$ of the whole kernel length) after milling divided by the weight of PGR sample. The equation was calculated as shown in Equation (2) [10].

$$
H R Y=\left[W t_{\text {whole rice }} / W t_{\text {raw rice }]} 100\right.
$$

Where, $W t_{\text {whole rice }}$ is the weight of unbroken white rice kernels $(\mathrm{g}), W t_{\text {raw rice }}$ is the weight of PGR sample before milling $(\mathrm{g})$

\subsubsection{Whiteness index}

The whiteness index (WI) was determined with a Hunter lab colorimeter (Hunter Lab, CR400 Chroma Meter, USA). It was determined by whiteness of PGR sample after milling in the linear range of 0 to 100 which was reported as the $\mathrm{L}^{*}, \mathrm{a}^{*}, \mathrm{~b}^{*}$ color scale. The equation was calculated as shown in Equation (3) [11].

$$
\left.W I=100-\left[\left(100-L^{*}\right)^{2}+\left(a^{*}\right)^{2}+\left(b^{*}\right)^{2}\right)\right]^{1 / 2}
$$

Where, $L^{*}$ is the value that represents the lightness, $a^{*}$ is the value that represents red and green, $b^{*}$ is the value that represents yellow and blue 


\section{Results and discussion}

\subsection{Changes of moisture content (MC) and grain temperature (GT)}

Figure 2 showed the changes in moisture content (MC) and grain temperature (GT) of PGR produced by different methods. From the results, it was found that the changes in MC and GT of the PGR in both methods were similar pattern. The MC was decreased rapidly at first period because it was the moisture at grain surface. The moisture at grain surface can be easily evaporated by heat convection. This result corresponded to the GT result, showing the rapid increase of GT. When the drying time increased, the $\mathrm{MC}$ was gradually decreased due to the fact that the evaporated moisture was occurred from the inside of grain to grain surface by heat conduction. This provided the slow increase of GT [12].

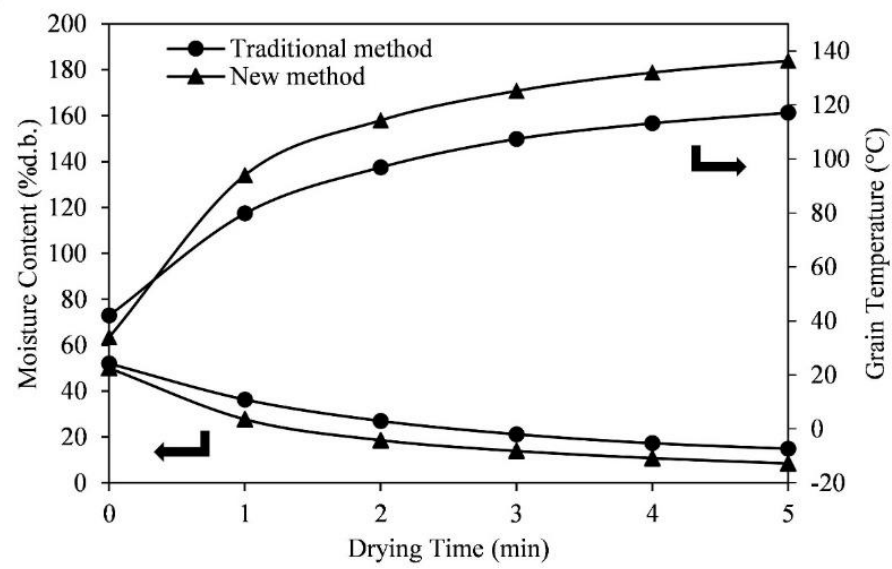

Fig. 2. Changes of moisture content and grain temperature in PGR produced by different methods.

When comparing the changes in moisture content and grain temperature of PGR between traditional method (germinating, steaming and drying using hot air fluidized bed) and new method (germinating and drying using hot air fluidized bed combined with halogen lamp), it was seemed that the changes in MC and GT of the PGR with new method were higher than these of the PGR with traditional method. This was because the fluidized bed provided the evaporation of moisture from the surface to the inside of grain [13]. In the same time, the halogen lamp provides the evaporation of moisture from the inside to grain surface. This caused the higher changes in MC and GT. However, the initial MC and GT before drying of PGR with traditional method ( $52 \%$ d.b. of MC and $42^{\circ} \mathrm{C}$ of GT) was higher than that of PGR with new method $\left(50 \%\right.$ d.b. of $\mathrm{MC}$ and $34^{\circ} \mathrm{C}$ of GT). It was because the PGR with traditional method received more moisture and heat content during steaming process [14]. Additionally, the higher initial MC in the PGR with traditional method caused the longer dying time (3 $\mathrm{min}$ ) to reach the MC of $22 \%$ d.b. . when comparing to the PGR with new method (1.5 min).

\subsection{Drying rate}

Figure 3 showed the comparison of drying rate of PGR produced by different methods. It was confirmed that the drying rate of PGR with new method was higher than that of PGR with traditional method because halogen lamps can increase the efficiency of moisture reduction by creating a drying mechanism in which the surface and inside of the grain at the same time as mentioned above, leading to high evaporation of moisture. 


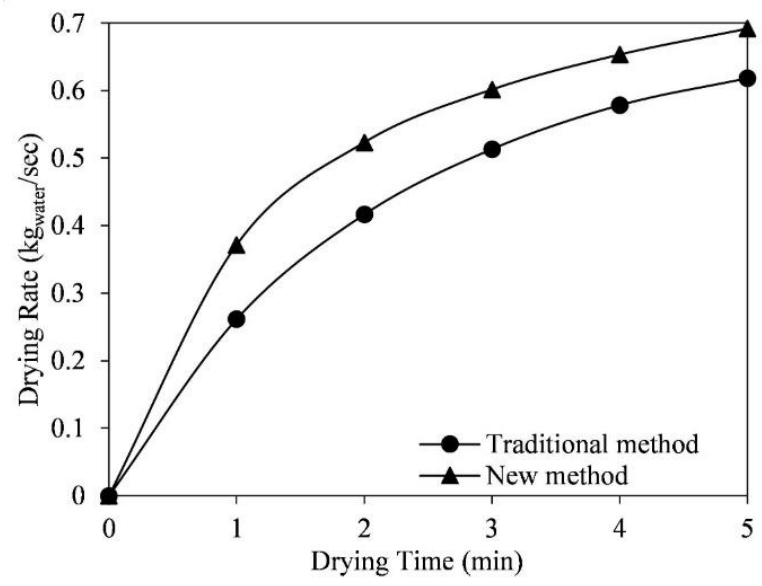

Fig. 3. The drying rate of PGR produced by different methods.

\subsection{The degree of gelatinization}

The result of degree of gelatinization (DG) in PGR produced by different methods was shown in Table 1. It appeared that $\Delta \mathrm{H}$ values of the PGR produced by traditional method and new method were lower than $\Delta \mathrm{H}$ value of the reference rice, indicating that the rice which was heated through a parboiling process occurred partially gelatinization, leading to increase of DG value $[15,16]$. When comparing the DG value between PGR produced by traditional method and PGR produced by new method, it was found that the DG value of PGR produced by traditional method was higher than that of PGR produced by new method. This is because of the initial MC. The initial MC of PGR produced by traditional method was higher, leading to the longer drying time and resulting in higher DG value.

Table 1. The degree of gelatinization in PGR produced by different methods.

\begin{tabular}{|c|c|c|c|c|c|}
\hline Sample & $\begin{array}{c}\text { Steaming } \\
\text { time } \\
(\mathbf{m i n})\end{array}$ & $\begin{array}{c}\text { Drying } \\
\text { temp. } \\
\left({ }^{\circ} \mathbf{C}\right)\end{array}$ & $\begin{array}{c}\text { Wattage of } \\
\text { halogen lamps } \\
(\mathbf{W})\end{array}$ & $\Delta \mathbf{H}(\mathbf{J} / \mathbf{g})$ & $\mathbf{D G}(\mathbf{\%})$ \\
\hline Reference rice & - & - & - & $10.65 \pm 0.00^{\mathrm{a}}$ & $0.0 \pm 0.00^{\mathrm{c}}$ \\
\hline $\begin{array}{c}\text { PGR with traditional } \\
\text { method }\end{array}$ & 15 & 170 & - & $0.35 \pm 0.01^{\mathrm{c}}$ & $96.7 \pm 0.09^{\mathrm{a}}$ \\
\hline $\begin{array}{c}\text { PGR with new } \\
\text { method }\end{array}$ & - & 170 & 4,000 & $0.66 \pm 0.02^{\mathrm{b}}$ & $93.8 \pm 0.16^{\mathrm{b}}$ \\
\hline
\end{tabular}

$a, b, c$ Means in the same column with different superscripts are significantly difference $(\mathrm{p}<0.05)$.

\subsection{Head rice yield}

Table 2. showed the percentage of head rice yield (HRY) of PGR produced by different methods. The result showed that the HRY value of reference rice was about $54.43 \%$ which was lower than that of PGR in both methods because of the heat process. The heat process provided the occurrence of starch gelatinization, leading to stronger structure modification in the grain and resulting in the increase of HRY in PGR. When comparing the HRY value of PGR between traditional method and new method, it was found that the HRY value of PGR in both methods was not different even though the degree of gelatinization of PGR in both methods was significantly different as shown in Table 1 . This may be due to the characteristics of gelatinization occurrence. The gelatinization of PGR with new method can 
occur on both outside and inside of grain at the same time [17], leading to the strong structure on both outside and inside of grain. On the other hand, the gelatinization of PGR with traditional method can only occur on the outside of grain.

Table 2. Percentage of head rice yield of PGR produced by different methods.

\begin{tabular}{|c|c|c|c|c|}
\hline Sample & $\begin{array}{c}\text { Steaming } \\
\text { time (min) }\end{array}$ & $\begin{array}{c}\text { Drying } \\
\text { Temp. }\left({ }^{\circ} \mathbf{C}\right)\end{array}$ & $\begin{array}{c}\text { Wattage of } \\
\text { halogen lamps } \\
\text { (W) }\end{array}$ & HRY (\%) \\
\hline Reference rice & - & - & - & $54.43 \pm 0.29^{\mathrm{b}}$ \\
\hline $\begin{array}{c}\text { PGR with traditional } \\
\text { method }\end{array}$ & 15 & 170 & - & $71.20 \pm 0.20^{\mathrm{a}}$ \\
\hline $\begin{array}{c}\text { PGR with new } \\
\text { method }\end{array}$ & - & 170 & 4,000 & $70.90 \pm 0.09^{\mathrm{a}}$ \\
\hline
\end{tabular}

${ }^{a, b}$ Means in the same column with different superscripts are significantly difference $(p<0.05)$.

\subsection{Whiteness index}

Figure 4 showed the whiteness index (WI) of PGR produced by different methods. The WI of the reference rice was 71.12 which was higher than that of PGR with traditional and new method. The low WI value of PGR was due to the non-enzymatic browning of the Maillard type [18]. When comparing the HRY value of PGR between traditional method and new method, it was found that the WI value of PGR produced by new method (31.83) was lower than that of PGR produced by traditional method (32.37). This was due to higher GT during heat process. In addition, the WI value of PGR produced by new method was in the range of PR standard which was 23.33-32.20 [19].

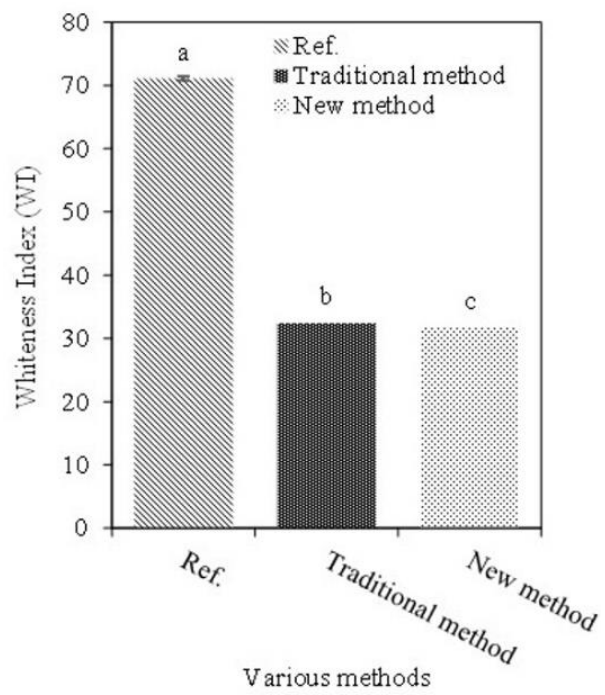

Fig. 4. The whiteness index of PGR produced by different methods.

\subsection{Specific Energy Consumption (SEC)}

Figure 5 showed the SEC value of PGR produced by different methods. The result showed that the total SEC value used in the traditional method was $18.97 \mathrm{MJ} / \mathrm{kg}$. When using the new method, the total SEC value was decreased about $21.51 \%$ with comparing the traditional 
method. The PGR production without steaming step can decrease the SEC value of $18.87 \%$ while the drying using hot air fluidized bed combined with halogen lamp provided the decrease of SEC value about $2.64 \%$ when comparing with the drying using hot air fluidized bed.

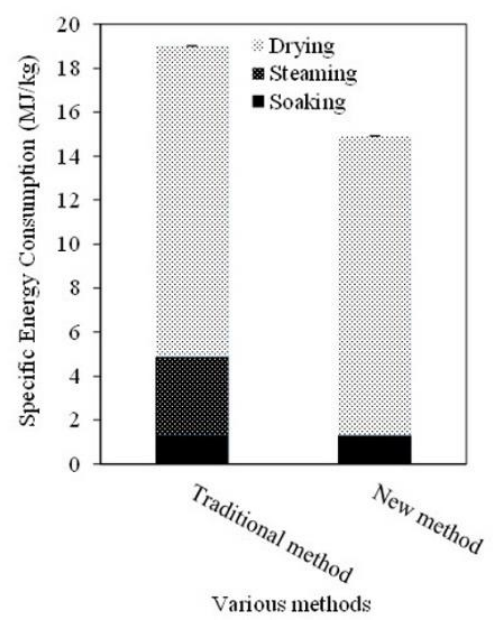

Fig. 5. The Specific Energy Consumption (SEC) of PGR produced by different methods.

\section{Conclusions}

The parboiled germinated rice (PGR) production by using new method (germinating and drying using hot air fluidized bed combined with halogen lamp) was noted in the present study to be more effective than doing by using traditional method (germinating, steaming and drying using hot air fluidized bed). It provided easier processing and good quality of PGR as same as traditional method. The low initial moisture content, short drying time and low whiteness index were occurred in the PGR with new method. The lower degree of gelatinization in PGR was also found. However, the new method provided the higher drying rate, leading to higher increase of grain temperature. The head rice yield in both PGR with new method and traditional method was not different. In addition, the Specific Energy Consumption (SEC) of PGR with new method was lower than that of PGR with traditional method.

The authors would like to thank the Agricultural Research Development Agency (Public Organization) for supporting the study financially (PRP6205031740).

\section{References}

1. J. Buggenhout, K. Brijs, I. Celus, J.A. Delcour, J. Food Eng. 117, 304 (2013)

2. L.W. Lu, J. Monro, J. Lu, E. Rush, J. MDPI. 7, 207 (2018)

3. I.D. Choi, D.S. Kim, J.R. Son, C.I. Yang, J.Y. Chun, K.J. Kim, J. Agri. Chem. Biotech. 49, 95 (2006)

4. V. Kumar, J. Singh, N. Chauhan, S. Chandra, V. Kumar, M.K. Yadav, A Review, J. Pharm. Phytochem. 1727 (2018)

5. B.S. Sridhar, B. Manohar, J. Bio. Eng. 85, 173 (2003) 
6. E. Taghinezhad, M.H. Khoshtaghaza, S. Minaei, T. Suzuki, T. Brenner, Rice Sci. 23, 339 (2016)

7. C. Taechapairoj, I. Dhuchakallaya, S. Soponronnarit, S. Wetchacama, S. Prachayawarakon, J. Food Eng. 58, 67 (2003)

8. G. Sumnu, E. Turabi, M. Oztop, LWT. 38, 549 (2005)

9. W.E. Marshall, J.I. Wadsworth, L.R. Verma, L. Velupillai, Cereal Chem. 70, 226 (1993)

10. S. Soponronarit, A. Nathakaranakule, A. Jirajindalert, C. Taechapairoj, J. Food Eng. 75, 423 (2006)

11. S. Tirawanichakul, O. Bualuang, Y. Tirawanichakul, J. Sci. Technol. 34, 557 (2012)

12. N. Srisang, C. Phetkeri, P. Daungvilailux, in Proceedings of fortieth The IRES International Conference, 10 June 2016, Zurich, Switzerland (2016)

13. S.A. Mir, S.J.D. Bosco, J. Food Nutri. Sci. 4, 282 (2013)

14. T. Unpinit, V. Seithtanabutara, T. Kamsan, P. Kwakong, A. Artnaseaw, Kasem Bundit Eng. J. 7, 124 (2017)

15. T. Tumpanuvatr, W. Jittanit, V. Surojanametakul, J. Stored Prod. Res. 77, 177 (2018)

16. S. Tirawanichakul, S. Prachayawarakorn, W. Varanyanond, P. Tungtrakul, S. Soponronnarit, Drying Technol. 22, 1731 (2004)

17. O. Bualuang, Y. Tirawanichakul, S. Tirawanichakul, J. Food Process. Preserv. 37, 1118 (2013)

18. L. Lamberts, K. Brijs, R. Mohamed, N. Verhelst, J.A. Delcour, J. Agri.Chem. 54, 9924 (2006)

19. P. Wanitchang, J. Wanitchang, P. Wanitchang, in Proceedings of the Academic Symposium RMUTTO, ARU and RRU on Local Research Topic Advance towards ASEAN Community, Cholchan Pattaya Beach Resort, 14-16 May 2014, Chon Buri, Thailand (2014) 